\title{
IMPLEMENTASI SISTEM PENGENALAN WAJAH UNTUK KEAMANAN AKSES BERBASIS UBUNTU MENGGUNAKAN PYTHON
}

\author{
Fahrizal', Andri Maulana $^{2}$, Sari Dermawan Aritonang ${ }^{3}$, \\ ${ }^{1}$ Sistem Informasi, Universitas Bina Sarana Informatika \\ ${ }^{2}$ Sistem Informasi, STMIK Nusamandiri \\ 3 Teknologi Informasi, Universitas Bina Sarana Informatika \\ 1,2,3 J1. Kamal Raya No.18, RT.6/RW.3, Cengkareng Barat, Kecamatan Cengkareng, Kota Jakarta Barat, \\ Daerah Khusus Ibukota Jakarta 11730 \\ email: fahrizal.fzl@bsi.ac.id, andry.ayz@bsi.ac.id,fsariarios43@gmail.com
}

Article history

Received June 09, 2021

Revised June 20, 2021

Accepted June 27, 2021

Available online June 30, 2021

Keywords

Computer Vision,

OpenCv,

Face recognition,

Python,

Ubuntu

\section{Riwayat}

Diterima 09 Juni 2021

Revisi 20 Juni 2021

Disetujui 27 Juni 2021

Terbit 30 Juni 2021

Kata Kunci

Computer Vision,

OpenCv,

Face recognition,

Python,

Ubuntu

\begin{abstract}
Security is one of the most important needs for human beings in both the building and the house. For the development of security technology used face recognition. Face recognition is a system that identifies facial features that are capable of detecting familiar faces and unknown Faces. In this research is implemented with computer vision where the computer can see and understand so that it is information from an Image or video. This computer can also mimic the ability of human intelligence. To classify a face object using OpenCv with Haar Cascade Classifier algorithm and uses Python programming language. Application used face recognition program is PyCharm Community 2018 version 3 with Linux operating system Ubuntu 18.04.2 LTS version. The results showed that the accuracy of face recognition depends on the analysis of OpenCv and the classification of Cascade for computer vision process.
\end{abstract}

Abstrak
Keamanan merupakan salah satu kebutuhan yang sangat penting bagi
manusia baik di gedung maupun rumah. Untuk pengembangan teknologi
keamanan menggunakan face recognition. Face recognition adalah suatu
sistem yang mengidentifikasi fitur wajah yang mampu mendeteksi wajah
yang dikenal dan wajah tidak dikenal. Pada penelitian ini
diimplementasikan dengan komputer vision yang mana komputer dapat
melihat dan memahami sehingga mengekstrak informasi dari sebuah
gambar atau video. Komputer ini juga dapat meniru kemampuan
kecerdasan manusia. Untuk mengklasifikasi sebuah objek wajah,
menggunakan OpenCv dengan algoritma Haar Cascade Classifier dan
menggunakan bahasa pemrograman python. Aplikasi yang digunakan
program face recognition adalah PyCharm Community 2018 Versi 3
dengan sistem operasi Linux Ubuntu versi 18.04.2 LTS. Hasil penelitian
menunjukan bahwa akurasi dari face recognition tergantung pada
analisa OpenCv dan klasifikasi cascade untuk proses computer vision.

kepolisian, karena diterapkan dalam kasus keamanan, dibutuhkan sistem yang handal terhadap beberapa kondisi, seperti : pengaruh latar belakang gambar dan pose wajah.

Menurut (Purwanto, Dirgantoro, \& Jati, 2015) mengemukakan bahwa "Rasa aman merupakan salah satu kebutuhan yang sangat penting bagi manusia dalam menghadapi era

JIKA $\mid 210$ 
teknologi saat ini. Keingintahuan pada keadaan atau kondisi hal yang dimiliki juga menjadi faktor penting bagi manusia untuk terus mengembangkan sistem keamanan gedung maupun rumah. Sistem dapat mendeteksi objek berupa wajah dari masukan citra. Sistem akan memerlukan masukan citra dari sebuah kamera keamanan. Setelah objek berupa wajah terdeteksi, sistem akan melakukan pencocokan wajah dengan gambar wajah yang terdapat pada database sistem. Dari pengolahan data, sistem akan menghasilkan logika yang digunakan pada proses selanjutnya dalam sistem keseluruhan. Sistem merupakan penerapan dari Computer Vision dalam sistem keamanan gedung atau rumah. Sistem akan mengambil citra dari masukan berupa video".

Mengenali wajah dalam sebuah gambar atau foto, bagi manusia merupakan hal yang mudah tetapi tidak demikian untuk komputer, agar dapat mengenali wajah manusia diperlukan perlakuan khusus sehingga ketika diberi input sebuah gambar atau foto, komputer dapat mendeteksi apakah dalam gambar tersebut terdapat sebuah gambar wajah atau tidak dan mengenali wajah tersebut. Sistem ini juga membutuhkan peran sistem kecerdasan buatan agar komputer dapat memiliki keputusan yang tepat dalam mengidentifikasi wajah.

Dalam tulisan ini akan dibahas tentang sistem pengenalan wajah (face recognition), yaitu pengenalan wajah dengan citra banyak wajah sehingga diharapkan dapat menjadi suatu sistem keamanan yang handal sebagai pengganti sistem fingerprint untuk meminimalkan sentuhan untuk mencegah penyebaran COVID19 yang sedang menjadi wabah pandemi global saat ini. Diharapkan dengan metode face recognition, pengenalan banyak wajah ini dapat memperoleh tingkat akurasi tinggi.

Maksud dalam tulisan ini dapat dirumuskan sebagai berikut :

1. Merancang dan mengimplementasikan sistem pengenalan wajah dari tiap sumber dalam banyak wajah.

2. Mendapatkan ciri yang membedakan wajah manusia dengan metode face recognition.
3. Menganalisa face recognition dengan menggunakan metode OpenCV.

\section{LITERATUR}

Sebagai referensi dalam penelitian ini memperoleh literatur dari beberapa buku dan penelitian sebelumnya yaitu:

1. Jurnal dengan judul "Sistem Pengenalan Wajah Secara Real-Time dengan Adaboost, Eigenface PCA \& MySQL" yang ditulis oleh Dodit Suprianto dkk, dalam penelitian pada jurnal tersebut pengenalan wajah dilakukan melalui tahap face detection, feature extraction dan face recognition, selanjutnya dicocokkan dengan data profil yang tersimpan di dalam database. Pendeteksian wajah menggunakan metode Adaboost, pengenalan wajah menggunakan metode Eigenface PCA dan database MySQL untuk menyimpan informasi profile. Penggunaan metode tersebut untuk pengenalan wajah pada kondisi real time dengan perbedaan jarak antara sensor dan wajah, posisi wajah, intensitas cahaya yang mengenai wajah, mimik muka dan atribut wajah dalam penelitian ini memberikan tingkat keberhasilan sebesar $80 \%$ dalam mengidentifikasi wajah.

2. Jurnal berjudul "Metode Face recognition untuk Identifikasi Personil Berdasar Citra Wajah bagi Kebutuhan Presensi Online Universitas Negeri Semarang" yang ditulis oleh Luthfi Maslichul Kurniawan, pada penelitian tersebut dikembangkanlah sebuah sistem face recognition yang dirancangbangun menggunakan bahasa pemrograman Python dan pustaka OpenCV. Hasil dari rancang bangun ini adalah sistem face recognition yang mampu berjalan secara otomatis di komputer server untuk membaca basis data presensi, mengolah foto-foto yang tersimpan pada basis data tersebut, mendeteksi wajah pada foto-foto yang diolah kemudian menampilkan hasilnya pada tabel basis data presensi untuk diolah dalam bentuk skor deteksi wajah yang tampil di rekapitulasi presensi online pegawai.

3. Jurnal berjudul "Implementasi Face recognition Pada Absensi Kehadiran Mahasiswa Menggunakan Metode Haar Cascade Classifier" yang ditulis oleh Munawir 
Munawir, Liza Fitria, Muhammad Hermansyah. Metode yang digunakan dalam penelitian ini adalah Haar Cascade Classifier. Terdapat 125 data training wajah dari 25 orang mahasiswa yang telah diinputkan kedalam sistem. Pengujian dilakukan dengan cara pengenalan satu wajah dan banyak wajah (multiple face recognition) sekaligus. Hasil pengujian menunjukkan bahwa tingkat akurasi pengenalan pada satu wajah dengan 25 data testing wajah didapatkan nilai akurasi sebesar $76 \%$, sedangkan pengenalan pada banyak wajah didapatkan nilai akurasi sebesar 33.3\%.

4. Buku berjudul "Applied Natural language processing with Python. Implementing Machine learning and Deep Learning Algorithms for Natural language processing yang disusun oleh Beysolow II, T. dalam buku tersebut membahas tentang pemanfaatan kemampuan AI untuk Natural language processing (NLP), yang dapat melakukan tugas-tugas seperti pemeriksa ejaan, peringkasan teks, klasifikasi dokumen, dan generasi bahasa alami. Dalam buku tersebut, mempelajari keterampilan untuk menerapkan metode ini dalam infrastruktur yang lebih besar untuk mengganti kode yang ada atau membuat algoritma baru. Penerapan Natural language processing menggunakan Python dimulai dengan meninjau konsepkonsep machine learning yang diperlukan sebelum membahas berbagai masalah NLP. Setelah membaca buku tersebut, Pembacanya akan memiliki keterampilan untuk menerapkan konsep-konsep ini di lingkungan sendiri.

\section{METODE PENELITIAN}

Agar lebih terarah, metodologi yang digunakan dalam penelitian ini yaitu: algoritma Haar Cascade Classifier yang diusulkan oleh Paul Viola dan Michael Jhon pada jurnalnya yang berjudul "Rapid Object Detection using a Boosted Cascade of Simple Features' yang terdiri atas:

\section{Haar feature selection}

Yaitu dengan cara menentukan ada atau tidaknya haar feature
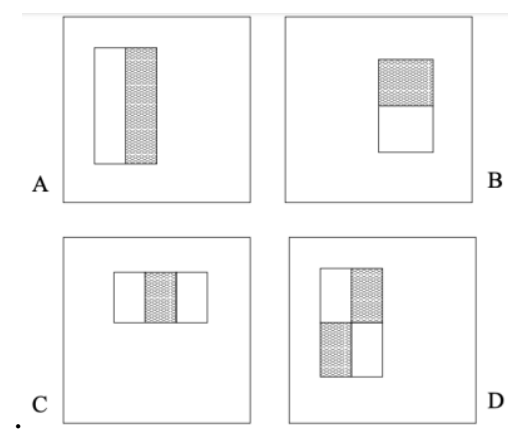

Gambar 1. contoh haar feature detection windows

Gambar 1 menunjukan contoh feature persegi panjang yang ditampilkan relatif terhadap detection window terlampir. Jumlah piksel yang terletak pada persegi panjang putih dikurangi dari jumlah piksel dalam persegi panjang abu-abu. fitur dua persegi panjang ditunjukkan pada (A) dan (B). gambar (C) menunjukkan fitur tiga persegi panjang, dan (D) fitur empat persegi panjang Jumlah piksel yang terletak di dalam putih.

\section{Creating integral Images}

yaitu membuat gambar integral dari gambar keseluruhan hasil dari deteksi ada atau tidaknya haar feature. dengan menggunakan rumus integral Image.

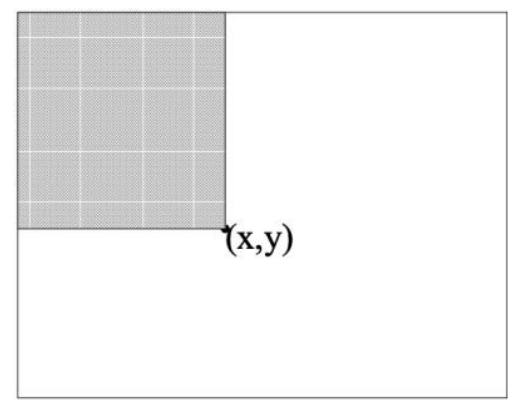

Gambar 2 nilai dari integral Image pada titik $(x, y)$ adalah jumlah dari keseluruhan piksel ujung atas ke kiri.

$$
i i(x, y)=\sum_{x^{l} \leq x, y \leq y}^{n} i\left(x^{l}, y^{l}\right)
$$

Dimana ii $(x, y)$ adalah integral Image dan $i\left(x^{l}, y^{l}\right)$ adalah gambar asli 


\section{Adaboost training}

Yaitu melakukan training terhadap komputer untuk pendeteksian object, dalam hal ini yaitu object wajah, adapun proses Adaboost training ini terdiri atas feature discussion, learning discussion, learning result, training a cascade of classifiers.

\section{HASIL DAN PEMBAHASAN}

Penelitian ini merupakan implementasi aplikasi dalam bentuk eksperimen. Adapun langkah awal yang diperlukan adalah membuat sebuah aplikasi yang mampu membedakan wajah untuk mendapatkan nilai keakuratan. Nilai keakuratan tersebut didapat dari kemampuan pemrosesan sebuah data oleh komputer vision. Pada bagian ini akan diuraikan jenis dan cara mendapatkan jenis dan cara mendapatkan data, serta cara pemrosesan data dan kerangka penelitian.

\section{Tinjauan Kasus}

Sistem keamanan dengan menggunakan CCTV (Closed Circuit Television) yang menyiratkan sinyal buatan tertutup atau tersembunyi, berbeda dengan sinyal siaran TV biasa. CCTV digunakan untuk keamanan dan juga digunakan secara luas di berbagai lokasi. Dalam peninjauan kasus ini yang perlu diperhatikan yaitu bagaimana deteksi wajah yang terekam oleh kamera CCTV hanya mampu melihat gambar sekilas dan merekam gerak gerik yang sudah direkam tetapi tidak mampu mengenal lebih akurat gambar yang ada di kamera.

\section{Spesifikasi Rancangan Program}

Dalam spesifikasi rancangan program ini memberikan tentang gambaran mengenai program yang akan dibuat, yang terdiri dari spesifikasi bentuk masukan, spesifikasi bentuk keluaran, spesifikasi file, spesifikasi program dan flowchart. untuk lebih jelas spesifikasi rancangan program ini akan dijelaskan kedalam beberapa sub pembahasan.

\section{Spesifikasi Rancangan Program}

Dalam spesifikasi rancangan program ini memberikan tentang gambaran mengenai program yang akan dibuat, yang terdiri dari spesifikasi bentuk masukan, spesifikasi bentuk keluaran, spesifikasi file, spesifikasi program dan flowchart. untuk lebih jelas spesifikasi rancangan program ini akan dijelaskan kedalam beberapa sub

\section{Nama Direktori : TA}

Fungsi :Sebagai interface awal dan mengeksekusi fungsi- fungsi pada aplikasi face recognition.

Media :Terminal atau Nautilus file manager.

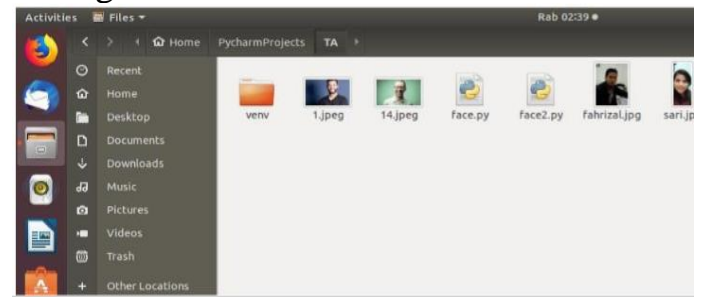

Gambar 3 Interface awal

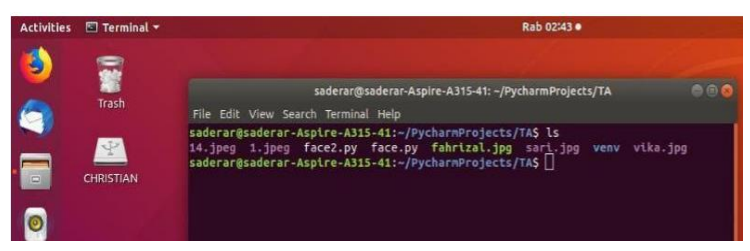

Sumber : Dokumen Pribadi

Gambar 4 Interface awal dalam bentuk CLI (Command Line Interface)

Spesifikasi Bentuk Masukan

Spesifikasi bentuk Masukan merupakan rangkaian data yang masuk kedalam sistem dan diproses oleh algoritma Machine learning sehingga menghasilkan sesuatu Output. Adapun spesifikasi bentuk masukan sebagai berikut :

\section{Nama Direktori : TA}

Fungsi : Sebagai label dari kumpulan gambar atau foto yang berupa data wajah yang akan di kenali (Known Face)

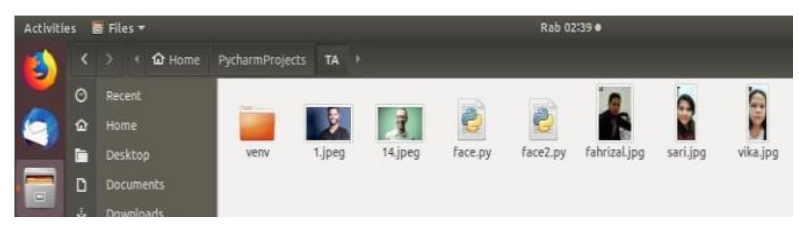

Gambar 5 Kumpulan gambar yang di kenal (Known Face) 
Spesifikasi Bentuk Keluaran

Spesifikasi bentuk keluaran adalah dokumen yang dihasilkan dari proses

Tabel 1 Spesifikasi bentuk keluaran spesifikasi bentuk masukan. Adapun bentuk keluaran ditunjukkan pada tabel berikut:

\begin{tabular}{|l|l|l|l|l|l|}
\hline $\begin{array}{l}\mathrm{N} \\
\mathrm{o}\end{array}$ & Nama & Fungsi & Tujuan & Media & Frekuensi \\
\hline 1 & $\begin{array}{l}\text { Image } \\
\text { processing ke } \\
\text { Face detection }\end{array}$ & $\begin{array}{l}\text { Tahapan awal dalam } \\
\text { pemrosesan gambar. }\end{array}$ & User & $\begin{array}{l}\text { Termina } \\
\text { l }\end{array}$ & $\begin{array}{l}\text { melakukan } \\
\text { training pada } \\
\text { dataset yang } \\
\text { disiapkan. }\end{array}$ \\
\hline 2 & $\begin{array}{l}\text { Output Face } \\
\text { Recognize } \\
\text { pada Image }\end{array}$ & $\begin{array}{l}\text { Sebagai tahap } \\
\text { pengujian dari dataset } \\
\text { yang telah diproses } \\
\text { oleh computer vision. }\end{array}$ & User & Termina & $\begin{array}{l}\text { Melakukan } \\
\text { pengujian pada } \\
\text { dataset yang telah } \\
\text { diproses. }\end{array}$ \\
\hline 3 & $\begin{array}{l}\text { Output Face } \\
\text { Recognize } \\
\text { pada Video } \\
\text { secara Real } \\
\text { time }\end{array}$ & $\begin{array}{l}\text { Sebagai tahap } \\
\text { pengujian dari dataset } \\
\text { yang telah di proses } \\
\text { oleh computer vision }\end{array}$ & User & Termina & $\begin{array}{l}\text { Melakukan } \\
\text { pengujian } \\
\text { terhadap dataset } \\
\text { yang telah } \\
\text { diproses. }\end{array}$ \\
\hline 4 & $\begin{array}{l}\text { Output Face } \\
\text { Recognize } \\
\text { pada Video } \\
\text { secara Real } \\
\text { time }\end{array}$ & $\begin{array}{l}\text { Sebagai tahap } \\
\text { pengujian dari dataset } \\
\text { yang telah di proses } \\
\text { oleh computer vision }\end{array}$ & User & Termina & $\begin{array}{l}\text { Melakukan } \\
\text { pengujian } \\
\text { terhadap dataset } \\
\text { yang telah } \\
\text { diproses }\end{array}$ \\
\hline 5 & $\begin{array}{l}\text { Output Face } \\
\text { Recognize } \\
\text { pada Video } \\
\text { secara } \\
\text { Realtime }\end{array}$ & $\begin{array}{l}\text { Sebagai tahap } \\
\text { pengujian dari dataset } \\
\text { yang telah di proses } \\
\text { oleh computer vision }\end{array}$ & User & Termina & $\begin{array}{l}\text { Melakukan } \\
\text { pengujian } \\
\text { terhadap dataset } \\
\text { yang telah } \\
\text { diproses. }\end{array}$ \\
\hline
\end{tabular}

\section{Spesifikasi File}

1. Spesifikasi File face.py

Nama File : face.py

Akronim : Face recognition on

Image

Fungsi

\section{: Face recognition} pada sebuah gambar atau foto

Tipe File : Output File

Akses File : Random

Media : Solid State Drive (SSD)

Software : PyCharm Community edition 2018 Versi 3.

2. Spesifikasi File face2.py

Nama File : face2.py
Akronim
: Face recognition on real time video
Fungsi
: Face recognition pada sebuah video secara real time.
Tipe File : Output File
Akses File : : Solid State Drive (SSD)
Software

$$
\begin{array}{lr}
\text { Community } & \text { PyCharm } \\
\text { Edition } \\
2018 \text { Versi } 3
\end{array}
$$

\section{HIPO (Hierarchy Input Process Output)}

Dalam spesifikasi rancangan program diperlukan suatu struktur guna memahami 
fungsi dari sistem, input ke suatu program dan Output yang dihasilkan.

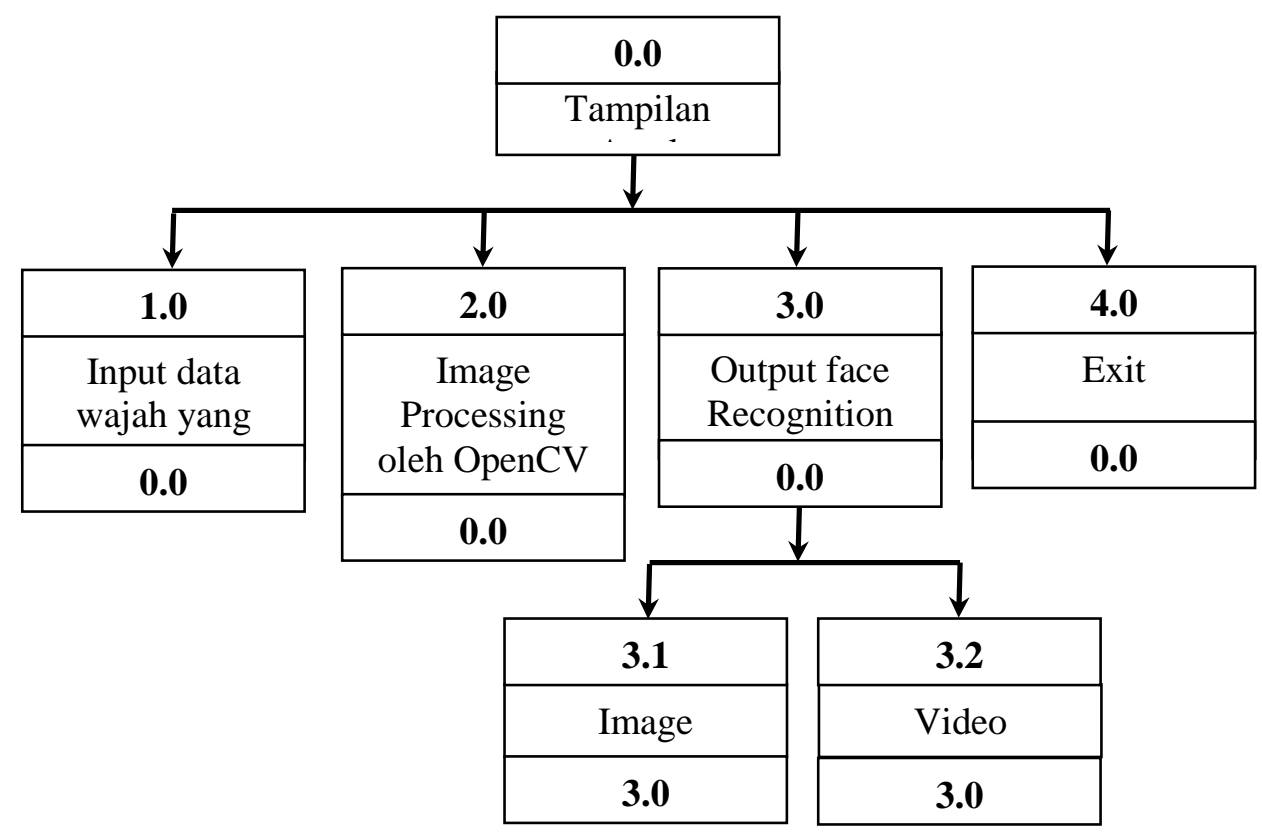

Gambar 6 HIPO (Hierarchy Input Process Output)

\section{Spesifikasi Program}

Spesifikasi program ini menjelaskan nama program dan fungsi masing masing program yang sebelumnya telah digambarkan dalam bentuk HIPO.

1. Spesifikasi program Output Face recognition on Image

Nama Program : Output Face recognition on Image

Akronim : recognize.py

Fungsi : Face recognition pada gambar atau foto

Bahasa Program : Phyton

Proses : Masukan foto atau gambar yang akan diuji ke dalam folder atau direktori "Images" Eksekusi file python face.py untuk melakukan Face recognition on Image dengan tambahan parameter di terminal dan nama file tersebut beserta format
2. Spesifikasi program Output Face recognition on real time video

Nama Program :Output Face recognition on real time video

Akronim :recognize_video.py

Fungsi :Face recognition pada sebuah video secara real time

Bahasa Program :Phyton

Proses :Eksekusi file python face.py untuk melakukan Face recognition on on real time video dengan tambahan parameter di terminal

\section{Flowchart}

Sedangkan diagram alir / flowchart program yang dibuat seperti gambar IV.5 di bawah ini. 


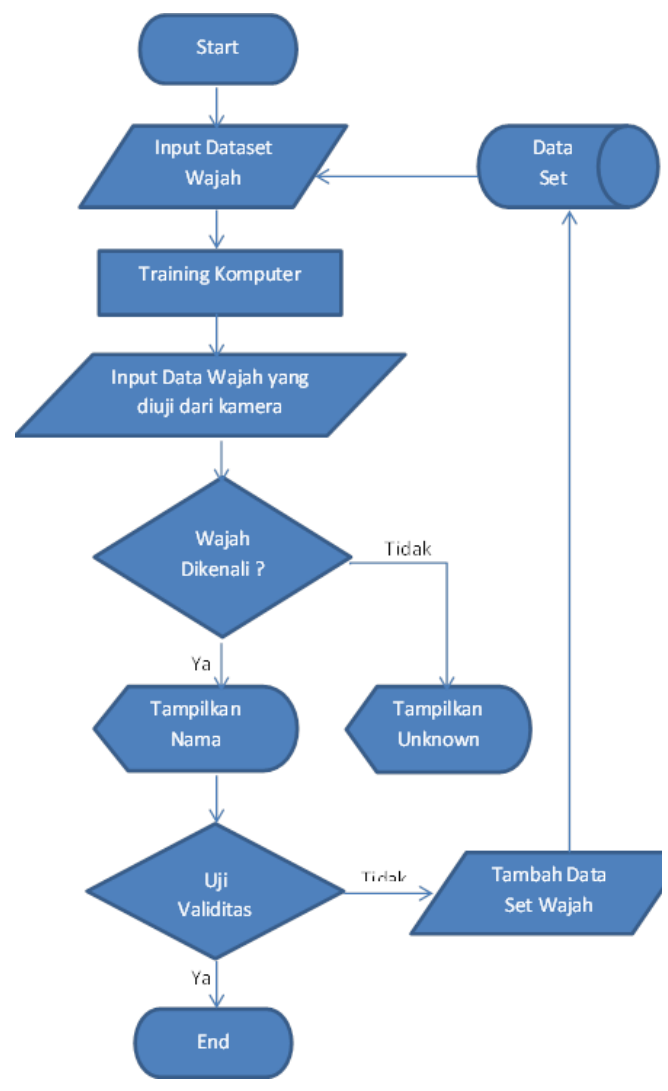

Gambar .7 Flowchart Program

\section{Sarana Pendukung Program}

a. Perangkat Keras (Hardware)

Perangkat keras (hardware)
adalah perangkat atau tools yang
diperlukan untuk proses
mengimplementasi aplikasi yang telah
dibuat. Adapun perangkat keras
(hardware) yang diperlukan oleh
aplikasi Face recognition ini antara
lain:

Laptop

Spesifikasi perangkat keras (hardware) yang digunakan untuk membuat aplikasi ini adalah :

a. Menggunakan Laptop Processor intel inside core $\mathrm{i} 3$

b. RAM (Random Access Memory) 4GB DDR4 .

c. VGA (Video Graphic Adapter) AMD Radeon R5

\section{b. Perangkat Lunak (Software)}

Perangkat lunak (software) adalah suatu aplikasi yang digunakan dalam proses pengimplementasian sistem atau aplikasi yang akan dibuat. Adapun perangkat lunak (software) yang diperlukan oleh aplikasi Face recognition dalam pembuatannya antara lain :

Sistem Operasi

a. Linux Ubuntu dengan Desktop Environment GNOME Versi 18.04.2 LTS (Long Term Support) Codename Bionic Beaver.

b. Kernel v5.1.16

c. PyCharm Community Edition 2018 Versi 3

d. Nautilus File Manager.

Tabel 2. Pengujian Black Box Testing

\begin{tabular}{|l|l|l|l|l|}
\hline No & Skenario & Test Case & Hasil yang diinginkan & Keterangan \\
\hline 1 & $\begin{array}{l}\text { Tampilan hasil } \\
\text { proses Output } \\
\text { Face detection } \\
\text { pada Image }\end{array}$ & $\begin{array}{l}\text { Dengan mengetikkan } \\
\text { nama file Image di CLI } \\
\text { Menampilkan jumlah } \\
\text { wajah yang dideteksi dan } \\
\text { ditapilkan pada CLI }\end{array}$ & $\begin{array}{l}\text { Program menampilkan } \\
\text { jumlah wajah yang } \\
\text { dideteksi dan ditapilkan } \\
\text { pada CLI }\end{array}$ & berhasil \\
& & \\
\hline
\end{tabular}




\begin{tabular}{|l|l|l|l|l|}
\hline 2 & $\begin{array}{l}\text { Hasil pengujian } \\
\text { Output Face } \\
\text { detection pada } \\
\text { Image }\end{array}$ & Memasukkan Image & $\begin{array}{l}\text { Program menampilkan } \\
\text { gambar wajah tanpa } \\
\text { background (auto crop) }\end{array}$ & berhasil \\
\hline 3 & $\begin{array}{l}\text { Tampilan hasil } \\
\text { proses Output } \\
\text { Face recognition } \\
\text { pada Video }\end{array}$ & $\begin{array}{l}\text { Mengarahkan kamera } \\
\text { pada wajah yang telah } \\
\text { didaftarkan pada program } \\
\text { untuk dikenali (Known } \\
\text { Face) }\end{array}$ & $\begin{array}{l}\text { Program mengenali } \\
\text { wajah dan } \\
\text { menampilkan nama } \\
\text { yang benar pada wajah } \\
\text { tersebut secara realtime }\end{array}$ & berhasil \\
\hline 4 & $\begin{array}{l}\text { Hasil pengujian } \\
\text { Output Face } \\
\text { recognition pada } \\
\text { video dengan } \\
\text { wajah yang } \\
\text { dikenal }\end{array}$ & $\begin{array}{l}\text { Mengarahkan kamera } \\
\text { pada lebih dari satu wajah } \\
\text { yang telah didaftarkan } \\
\text { pada program untuk } \\
\text { dikenali (Known Face) }\end{array}$ & $\begin{array}{l}\text { Program mengenali } \\
\text { wajah dan } \\
\text { menampilkan nama } \\
\text { yang benar pada wajah } \\
\text { tersebut secara real } \\
\text { time }\end{array}$ & berhasil \\
\hline 5 & $\begin{array}{l}\text { Hasil pengujian } \\
\text { Output Face } \\
\text { recognition pada } \\
\text { video dengan } \\
\text { wajah yang } \\
\text { dikenal dan tidak } \\
\text { dikenal }\end{array}$ & $\begin{array}{l}\text { Mengarahkan video pada } \\
\text { wajah yang dikenal dan } \\
\text { tidak dikenal }\end{array}$ & $\begin{array}{l}\text { Program menampilkan } \\
\text { nama yang benar pada } \\
\text { wajah yang dikenal dan } \\
\text { menampilkan Unknown } \\
\text { pada wajah yang tidak } \\
\text { dikenal }\end{array}$ & berhasil \\
\hline
\end{tabular}

Dari hasil pengujian diatas maka didapatkan hasil dengan menggunakan program ini cukup akurat dengan persentase $80 \%$ dengan kecepatan proses paling lambat sekitar 1 detik, dapat mendeteksi wajah pada file Image, bahkan dapat mendeteksi lebih dari satu wajah namun belum dapat membedakan antara gambar wajah dengan wajah asli dari kamera langsung. Selain itu pengujian belum dilakukan untuk membedakan wajah saudara kembar identik.

Program juga dapat mengenali kembali wajah-wajah yang telah didaftarkan pada sistem dan menampilkan identitas nama dari wajah yang tampil tersebut dengan benar. Dan mengenali juga wajah yang belum terdaftar pada sistem sebagai wajah yang tidak dikenal/ unknown Face. Hasil-hasil pengujian tersebut terlihat pada gambar-gambar lampiran dibawah ini.

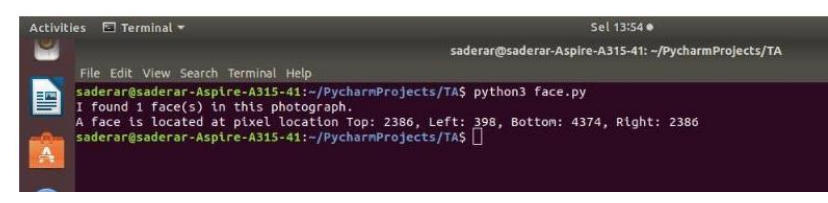

Gambar 8. Tampilan hasil proses Output Face detection pada Image di CLI

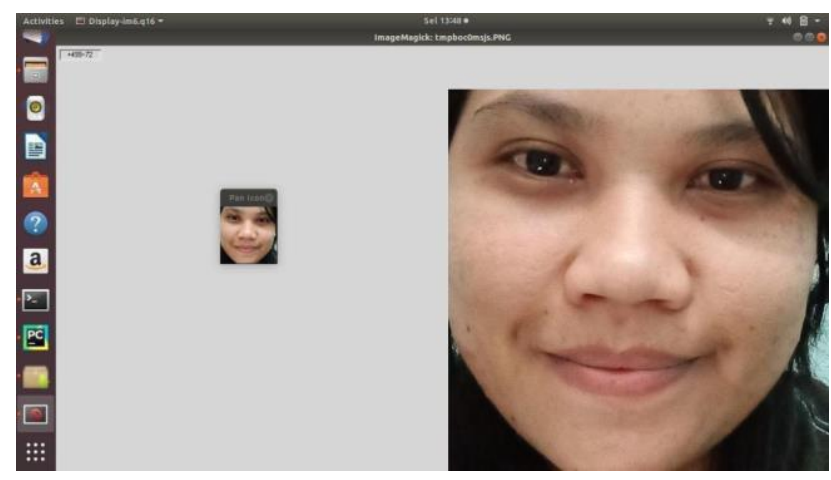

Gambar 9. Hasil pengujian Output Face detection pada Image 


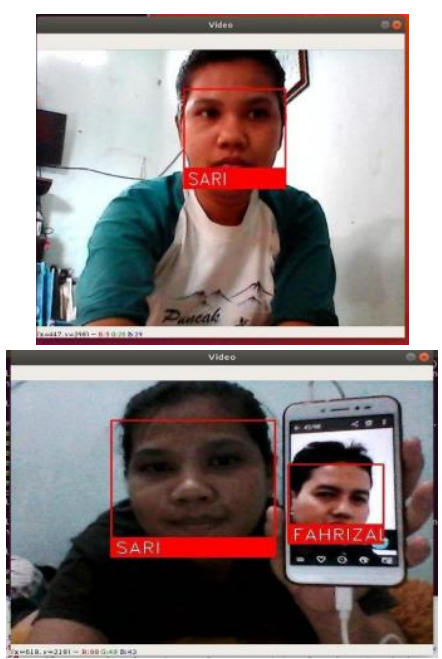

Gambar 10. Tampilan hasil proses Output Face recognition pada Video

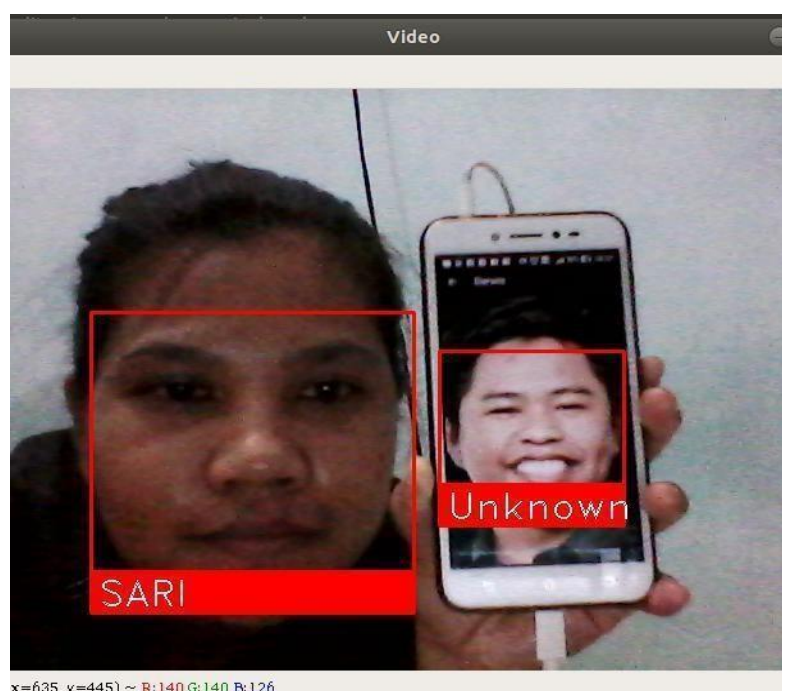

$\underline{x}=635 . v=4451 \sim \mathrm{R}: 140 \mathrm{G}: 140 \mathrm{~B}: 126$

Gambar 11. Hasil pengujian Output Face recognition pada video dengan wajah yang dikenal dan tidak dikenal

\section{KESIMPULAN}

Berdasarkan pembahasan dan pengujian program face recognition, maka menghasilkan kesimpulan sebagai berikut:

1. Semakin banyak gambar yang diambil sebagai data training dapat mempengaruhi ketajaman analisa komputer dalam mengenali objek yang diuji.

2. Kualitas kamera dapat mempengaruhi nilai keakuratan komputer dalam mengenali suatu objek.

3. System Face recognition sangat membantu keamanan di sebuah ruangan perkantoran sekolah maupun gedung. Dan untuk pengembangan selanjutnya diharapkan dapat digunakan juga sebagai bagian dari sistem presensi otomatis menggunakan kamera dan pendeteksi wajah ini yang terhubung dengan basis data sistem presensi.

\section{REFERENSI}

\section{II, T. B. (2018). Applied Natural} language processing with Python: Implementing Machine learning and Deep Learning Algorithms for Natural Language Processing, 158. Retrieved from https://books.google.iq/books?h $1=$ en $\& 1 \mathrm{r}=\& \mathrm{id}=\mathrm{FDBuDwAAQB}$ AJ\&oi $=$ fnd \&pg $=$ PR $5 \& d q=$ Beys olow+II,+T.,+2018.+Applied+ Natural+Language+Processing+ with+Python:+Implementing+ Machine+Learning+and+Deep+ Learning+Algorithms+for+Natu ral+Language+Processing. + Apr ess\&ots $=$ P5cG-Z7

Kurniawan, L. M. (2015). Metode Face recognition untuk Identifikasi Personil Berdasar Citra Wajah bagi Kebutuhan Presensi Online Universitas Negeri Semarang. Scientific Journal of Informatics, 1(2), 210-220.

https://doi.org/10.15294/sji.v1i2 .4027

Viola, P., \& Jones, M. (2001). Rapid object detection using a boosted cascade of simple features.

Proceedings of the IEEE Computer Society Conference on Computer Vision and Pattern Recognition, 1(February). https://doi.org/10.1109/cvpr.200 1.990517 
Purwanto, P., Dirgantoro, B., \& Jati, A. N. (2015). Implementasi Face Identification Dan Face recognition Pada Kamera Pengawas Sebagai Pendeteksi

Bahaya. EProceedings of Engineering, 2(1), 718-724. Retrieved from https://libraryeproceeding.telko muniversity.ac.id/index.php/eng ineering/article/view/2045

Suprianto, D. (2013). Sistem Pengenalan Wajah Secara RealTime. Sistem Pengenalan Wajah Secara Real-Time
Dengan Adaboost, Eigenface $P C A \& M y S Q L, 7(2), 179-184$.

Wang, Y.-Q. (2014). An Analysis of the Viola-Jones Face detection Algorithm. Image processing On Line, 4, 128-148. https://doi.org/10.5201/ipol.201 4.104

Xu, M. (2012). Robust object detection with real-time fusion of multiview foreground silhouettes. Optical Engineering, 51(4), 047202. https://doi.org/10.1117/1.oe.51. 4.047202 